\title{
Bridging differing perspectives on technological platforms: Toward an integrative framework
}

\author{
Annabelle Gawer* \\ Imperial College Business School, Imperial College London, South Kensington Campus, London SW7 2AZ, United Kingdom
}

\section{A R T I C L E I N F O}

\section{Article history:}

Received 15 November 2010

Received in revised form 24 February 2014

Accepted 6 March 2014

Available online $\mathrm{xxx}$

\section{Keywords:}

Platforms

Double-sided markets

Modularity

Economies of scope

Organizations

\begin{abstract}
A B S T R A C T
An integrative framework is proposed to advance management research on technological platforms, bridging two theoretical perspectives: economics, which sees platforms as double-sided markets, and engineering design, which sees platforms as technological architectures. While the economic perspective informs our understanding of platform competition, the engineering design perspective informs our view of platform innovation. The article argues that platforms can be usefully conceptualized as evolving organizations or meta-organizations that: (1) federate and coordinate constitutive agents who can innovate and compete; (2) create value by generating and harnessing economies of scope in supply or/and in demand; and (3) entail a modular technological architecture composed of a core and a periphery. In support of this conceptualization, a classification system is presented, indicating that technological platforms appear in a variety of organizational forms: within firms, across supply chains, and across industry innovation ecosystems. As an illustration, the framework is then applied to derive a simple model highlighting patterns of interaction between platform innovation and competition, yielding hypotheses that could be tested empirically by future scholars.
\end{abstract}

(C) 2014 Elsevier B.V. All rights reserved.

\section{Introduction}

The digital sector provides several widely recognized examples of technological platforms and their associated "platform leader" (Gawer and Cusumano, 2002) or "keystone firm" (Iansiti and Levien, 2004), such as Google, Apple, or Facebook. Each of these firms plays a central, orchestrating role within a network of firms and individual innovator-developers that have come to be collectively referred to as the platform's "innovation ecosystem" (Adner and Kapoor, 2010; Nambisan and Sawhney, 2011) or "ecologies of complex innovation" (Dougherty and Dunne, 2011).

Despite the importance of technological platforms, the management research agenda has been limited and divided. It has been dominated by two distinct theoretical perspectives: one inspired from economic theory, and the other from engineering design. These perspectives have developed separately, and have conceptualized platforms either as types of markets (two-sided markets, Rochet and Tirole, 2003) or as modular technological architectures (Baldwin and Woodard, 2009). Rooted in different

\footnotetext{
* Tel.: +442075949174.

E-mail address: a.gawer@imperial.ac.uk
}

intellectual traditions, and based on distinct assumptions, these theories have focused on the different directional forces platforms respond to. While the economic perspective has yielded insights on platform competition, the engineering design perspective has focused on platform innovation.

While useful starting points, these differing perspectives have not helped articulate how platform competition and platform innovation interact. This is a serious issue, as in reality platforms operate in ways that often combine innovation with increased competitive tensions within their ecosystems and/or across ecosystems. For example, in 2012, the social networking platform Facebook innovated on a new mobile phone "homescreen" application, Facebook Home, having used Android (Google's mobile phone operating system, itself an important technological platform) as a tool to build it. Facebook then positioned Home to take centre-stage in the end-user mobile phone experience, thereby expanding Facebook's presence in the mobile phone space, thus turning a formerly collaborative relationship with Google into a competitive one. In addition, Facebook has innovated in the domain of social search, where Google has innovated as well, establishing another space where these two firms will compete even more squarely for end-users' attention and sources of digital advertising revenues. These examples indicate that platform innovation and competition cannot be understood in isolation, and suggest that these forces interact to shape the evolution of platforms. 
The important issue of interaction between platform innovation and platform competition has recently begun to attract scholars' attention. Boudreau (2010) draws on the engineering design literature to study "open platform strategy and innovation". Meanwhile, Eisenmann et al. (2011) draw on economic analysis to present the competitive analysis of "platform envelopment" in terms of market entry and bundling. These studies are attentive to platform innovation as well as competition, nevertheless their differing framings reflect the remaining gap between the theoretical perspectives on platforms.

This article aims to bridge the dominant theoretical perspectives, and proposes a unified theoretical framework for research on technological platforms. Rather than interpreting platforms either as types of markets or as specific technological architectures, the argument developed in this paper culminates in a new conceptualization of platforms that sees platforms through an organizational lens, which combines a specification of structure with a focus on agency, yet does not impose a priori a fixed organizational form, recognizing the multiplicity of organizational contexts within which platforms can be found.

The paper's main thesis is that technological platforms can be usefully conceptualized as evolving organizations or metaorganizations ${ }^{1}$ that: (1) federate and coordinate constitutive agents who can innovate and compete; (2) create value by generating and harnessing economies of scope in supply or/and in demand; and (3) entail a modular technological architecture composed of a core and a periphery.

This article offers two main contributions. The first contribution is to bridge the economic double-sided market and the engineering design perspectives, by summarizing and comparing systematically their contributions, arguments, assumptions and limitations. I demonstrate that there has been an undetected conceptual commonality between the two, namely that platforms create value through economies of scope in supply and/or in demand. The second contribution is the justification and elaboration of the new theoretical framework that conceptualizes technological platforms as evolving organizations or meta-organizations composed of agents who can innovate and compete. Taking on board essential insights from the previous literatures yet relaxing unnecessary assumptions, this framework does not take a platform's organizational form as exogenous and fixed, and puts the focus on agents within platforms. These agents can be individuals or firms, and can play a variety of roles, these roles not being restricted a priori to being either always consumers (as in the double-sided market literature) or always collaborative innovators (as in the engineering design literature). By doing so, the framework makes explicit the micro-foundations of how platforms operate. This framework constitutes a useful contribution to the platforms literature, as it attempts to lay a theoretical foundation that will allow future scholars to make further incremental and cumulative development to platform research. In particular, the organizational lens on platforms will allow researchers to tap into the vast organizational theory literature to develop further insights on how platforms operate and evolve.

The remainder of the article is structured as follows. Section 2 summarizes and bridges the economics and engineering design and uncovers the centrality of supply and demand economies of scope in how platforms create value. Section 3 presents a classification system of three different categories of platforms (within

1 The concept of meta-organization, originally used by Ahrne and Brunsson (2005) to characterize organizations of organizations, was further clarified by Gulati et al. (2012). In this paper, we adopt Gulati et al. (2012)'s definition: a meta-organization is "an organization whose agents are themselves legally autonomous and not linked through employment relationships" (Gulati et al., 2012, p. 573).
Table 1

Platforms in economics and engineering design.

\begin{tabular}{|c|c|c|}
\hline Literature & Economics & Engineering design \\
\hline Conceptualization & Platforms as markets & $\begin{array}{l}\text { Platforms as } \\
\text { technological } \\
\text { architectures }\end{array}$ \\
\hline Perspective & Demand & Supply \\
\hline Focus & Competition & Innovation \\
\hline Value created through & $\begin{array}{l}\text { Economies of scope in } \\
\text { demand }\end{array}$ & $\begin{array}{l}\text { Economies of scope in } \\
\text { supply and innovation }\end{array}$ \\
\hline Role & $\begin{array}{l}\text { Coordinating device } \\
\text { among buyers }\end{array}$ & $\begin{array}{l}\text { Coordinating device } \\
\text { among innovators }\end{array}$ \\
\hline Empirical settings & ICT & Manufacturing and ICT \\
\hline
\end{tabular}

firms, across supply chains, and across industry innovation ecosystems), which is then used to develop the justification for a new conceptualization of platforms as organizations and its associated framework. Section 4 illustrates the framework by proposing a simple model of how platform innovation and competition interact along the organizational continuum of technological platforms. The paper concludes with a discussion of its contributions, limitations and avenues for further research.

\section{Technological platforms: conceptualizations from economics and engineering design}

Management research on technological platforms has been developed from two separate streams of academic literature: industrial economics (Rochet and Tirole, 2003; Evans et al., 2006; Armstrong, 2006) and engineering design (Meyer and Lehnerd, 1997; Krishnan and Gupta, 2001; Jiao et al., 2007). The economics perspective focuses on how platforms as markets mediate transactions across different customer groups and how network effects fuel platform competition. In contradistinction, the engineering design perspective views product platforms as technological designs that help firms generate modular product innovation. Table 1 summarizes and highlights the differences and similarities between the economics and the engineering perspectives on platforms.

\subsection{The economics perspective: platforms as markets}

Since the early 2000s, a section of the industrial organization economics literature has begun to develop theory on platforms, which have been variously referred to as "two-sided markets", "multi-sided markets", or "multi-sided platforms" (Rochet and Tirole, 2003, 2006; Evans, 2003; Rysman, 2009). Economists view platforms as special kinds of markets that play the role of facilitators of exchange between different types of consumers that could not otherwise transact with each other.

Essential to most economic definitions of multi-sided platforms are the existence of "network effects" that arise between the "two sides" of the market (Evans, 2003; Rochet and Tirole, 2003, 2006; Armstrong, 2006). For example, Armstrong (2006, p. 66) defines two-sided markets as "markets involving two groups of agents interacting via 'platforms' where one group's benefit from joining a platform depends on the size of the other group that joins the platform". Evans and Schmalensee (2008, p. 667) define two-sided platforms as "businesses in which pricing and other strategies are strongly affected by the indirect network effects between the two sides of the platform".

The concept of network effects is so central in this literature that Rysman (2009, p. 127) states that "in a technical sense, the literature on two-sided markets could be seen as a subset of the literature on network effects." Most models take network effects as exogenous and fixed, and see them as the fundamental drivers 
of platform competition. Network effects trigger a self-reinforcing feedback loop that magnifies incumbents' early advantages. Strong network effects can under certain conditions drive competition between platforms to a "winner-take-all" outcome (Eisenmann et al., 2006).

For an illustration of this self-reinforcing mechanism, consider the case of video games consoles and its compatible videogames: a technological platform (for example the Nintendo Wii game console) endowed with an initially larger installed base of end-users (gamers) will have the effect of increasing the incentives for developers of complementary products or services ${ }^{2}$ (here, video game developers) to join the Wii platform and develop Wii-compatible videogames; this increased provision of complements would, in turn, help to attract more end-users to the Wii platform.

The literature distinguishes between two main kinds of network effects: direct network effects and indirect network effects. Direct network effects, also called same-side network effects, arise when the benefit of a technology to a user depends positively on the number of other users of this technology, as for example in a telephone network, or the network of Skype users. Indirect network effects and the associated notion of cross-group network effects are precisely defined by Hagiu and Wright (2011, p. 5) as such: "A cross-group network effect arises if the benefit to users in at least one group (side A) depends on the number of other users in the other group (side B). An indirect network effect arises if there are cross-group network effects in both directions (from $A$ to $B$ and from $B$ to $A$ ) and side B's participation decision depends on the number of participants on side $A$ so that the benefit to a user on side $B$ depends (indirectly) on the number of users on side A." Indirect network effects therefore reflect a pre-existing underlying interdependency (and complementarity) between the demands from two or more types of consumers. This complementarity in turn fuels a self-reinforcing feedback loop of adoption "from both sides", that has the effect of reinforcing incumbent platform owners' early installed base advantages.

Network effects are sometimes characterized as demand-side economies of scale (Katz and Shapiro, 1986, p. 824; Parker and Van Alstyne, 2005, p. 149). I suggest however, to be more precise, that while direct network effects constitute demand-sides economies of scale, indirect network effects in fact constitute demand-side economies of scope, a point I shall return to in more detail in Section 2.2.

Platform competition in economics models is driven by the adoption of the platform by multiple consumer constituencies, itself fuelled by network effects. As the value of the platform stems principally from the access of "one side" to the "other side" of the platform, the question of platform adoption becomes "how to bring multiple sides on board" (Evans, 2003; Rochet and Tirole, 2006) while avoiding the "chicken-and-egg problem" (Caillaud and Jullien, 2003). Parker and Van Alstyne (2005), Rochet and Tirole $(2003,2006)$ and most others in this literature suggest that adequate pricing, involving the subsidizing of "one side" of the platform in order to attract the "other side" to join, solves this coordination problem.

The empirical evidence in this literature has generally confirmed the validity of the economic approach in explaining the difference in pricing and business models among various platform markets, drawing from examples generally taken from the ICT industry, the media advertising industry, or the payment industry (see for example Rysman, 2004; Evans et al., 2006; Wilbur, 2008).

2 I shall from now on use the word "complementor" (Brandenburger and Nalebuff, 1997 ) as a short hand (and synonym) for the longer phrase: "developer of complementary products or services".
In summary, the economic theoretical perspective posits that platforms fundamentally create value by acting as conduits between two (or more) categories of consumers who would not have been able to connect or transact without the platform. Platforms create value by coordinating these groups of consumers and in the economic view this coordination is effected through pricing. The value that consumers as well as the platform owner can capture increases with increasing customer bases, in a virtuous cycle of indirect network effects. These network effects, viewed as an essential feature of platforms, reflect exogenous interdependence of demand between consumer groups, and shape platform competition. The economic view helps explain why some platforms become dominant, and may even give rise to "winner-take-all" competitive outcomes under specific circumstances.

While quite influential, the economic perspective on platforms rests on strong, yet often implicit assumptions, which give rise to two main limitations. First, in most economic models of two-sided markets, platforms are taken to be both exogenous and fixed. As such, these models do not offer much insight into what determines how or why they would evolve. Second, the nature of the relationship between the platform owner and the two sides of the platform is reduced to that of a seller-buyer relationship, where both sides of the platform, whether they are end-users or innovative developers of complementary products, are equally seen and treated as simple consumers. The developers of complementary products or services are not seen as suppliers, or as innovators, but as consumers. A decision by complementors to innovate on top of a platform is viewed as a consumption choice, an adoption decision.

While this simplification may make sense if one describes the behaviour of dating bars facilitating the matching between men and women (a common motivating example in this literature), this assumption is problematic for technological platforms, which are the focus of this article. This reduction of the modality of interaction between platform complements developers and platform producers to a passive consumption relationship has several limiting consequences for those interested in how platforms evolve: (a) all forms of competitive interaction between a platform owner and its own complements developers are left unexamined (as outside the scope of these models); (b) the very existence of complementarity-in-demand between the different "consumer groups" (the foundational "network effects") is taken for granted, deemed exogenous, and assumed to be unchanging; (c) the existence of the platform itself is also taken for granted, exogenous and unchanging; (d) the impact of platform design on developers' incentives to innovate is left untreated.

The two-sided markets economic perspective offers therefore a static, demand-side view of platform competition (as understood as competition between platforms, not within platform ecosystems). It highlights well conditions under which some platforms can attain rapidly positions of sustained market dominance, but by and large does not address the issues of platform evolution and platform innovation.

While the thrust of the multi-sided literature is summarized above, recent developments in management research have extended it in directions that begin to challenge its static, demandside assumptions. For example, Eisenmann et al. (2009) enrich the multi-sided view by bringing in concepts from the supply side, referring to platforms as "multi-sided networks" that have both "demand-side users" and "supply-side users". Subsequently, Eisenmann et al. (2011) begin to address how platform competition can lead to platforms changing scope over time, in their presentation of "platform envelopment", a bundling strategy through which platforms attack their target by extending their functionalities through leveraging shared user relationships (demand-side economies of scope) as well as common components (supply-side economies of scope). 


\subsection{The engineering design perspective: platforms as technological architectures}

Industrial organization theorists were not the first to develop the concept of platforms. More than ten years before Rochet and Tirole's (2003) characterization of platforms as two-sided markets, the term was percolating through the new product development literature, where it soon gave rise to a well-developed theoretical perspective on platforms and their effect on innovation.

Ideals of rational production and systematic design of complex systems, combined with Simon (1962)'s suggestion that hierarchical and decomposable systems help mitigate the effects of complexity, nourished a set of interrelated literatures on new product development, operations and production management, and later on modularity, which I regroup under the label of engineering design perspective. These literatures have attempted to explore the implications of so-called "design hierarchy" (Clark, 1985) on methods of product development and production. It developed the concept of product platforms, and highlighted specific kinds of design choices on product architecture (Ulrich, 1995) that could help firms generate product families (Sanderson and Uzumeri, 1995) and innovate more quickly and systematically by using and re-using common assets (Krishnan and Gupta, 2001) as templates for product innovation.

For Wheelwright and Clark (1992, p. 73), the earliest management scholars to refer explicitly to the concept of platform, platforms are products that meet the needs of a core group of customers, but can be modified through the addition, substitution, or removal of features. For McGrath (1995), platforms are collections of common elements, especially technological ones, implemented across a range of products. Meyer and Lehnerd (1997) define a platform as a set of subsystems and interfaces forming a common structure from which a stream of products can be developed. Krishnan and Gupta (2001) define platforms simply as component and subsystem assets shared across a family of products, while Muffato and Roveda (2002) add the perspective of an intentionally planned and developed set of subsystems and interfaces from which products can be developed. Robertson and Ulrich (1998) propose a broader definition: the assets (components, processes, knowledge, people, or relationships) shared by a set of products.

These platform definitions all share the commonality of systematic re-use of components across different products within a product family, which allows economies of scope in production to occur. Hence, the systematic creation and harnessing of economies of scope in innovation can be seen as one fundamental principle of platform-based new product development.

"Economies of scope" (Panzar and Willig, 1975, 1981; Teece, 1980,1982 ) exist when the cost of joint production is less than the cost of producing each output separately. For the context of platform-based new product development, I propose to extend the concept of economies of scope in production to the concept of economies of scope in innovation. I define economies of scope in innovation as when the cost of jointly innovating on Product $A$ and $B$ is lower than the cost of innovating on A independently of innovating on $\mathrm{B}^{3}$

Empirical studies within the engineering design stream have identified such economies of scope can occur in a variety of industrial contexts (such as automotive manufacturing, aerospace engine manufacturing, consumer electronics), and a variety of organizational settings. For example, while early studies of manufacturing

\footnotetext{
3 While further development of this concept is outside the scope of this article, a similar concept is found in Bresnahan and Trajtenberg (1995)'s study of general purpose technologies when they formalize what they call "innovation complementarity".
}

platforms observed them within firms, research has also documented how manufacturing platforms were increasingly being shared across firms within supply-chains (Brusoni, 2005; Zirpoli and Becker, 2011; Zirpoli and Caputo, 2002; Brusoni and Prencipe, 2009; Sturgeon, 2002; Doran, 2003; Huang et al., 2005; MacDuffie, 2013; MacDuffie and Helper, 2006; Sako, 2009; Simpson et al., 2006; Tatsumoto et al., 2009). Most recently, technological platforms have been found to operate within even larger networks of firms that are not necessarily linked through buyer-supplier relationships - also known as "innovation ecosystems" (Adner and Kapoor, 2010; Nambisan and Sawhney, 2011) or "ecologies of complex innovation" (Dougherty and Dunne, 2011). Such industry platforms are then defined as '. . . a building block, providing an essential function to a technological system - which acts as a foundation upon which other firms, loosely organized in an innovation ecosystem, can develop complementary products, technologies or services' (Gawer, 2009a: 2; Gawer, 2009b: 54).

Platform design stands out as a common element across this set of organizational contexts (Huang et al., 2005; Simpson et al., 2006; Jiao et al., 2007). Gawer (2009c) and Baldwin and Woodard (2009) highlight that all observed platforms share a structural commonality: that of a modular technological architecture (Ulrich, 1995; Baldwin and Clark, 2000). ${ }^{4}$ Baldwin and Woodard (2009) present the most advanced attempt to characterize what is unique about platforms architectures: they view platforms as having a particular type of technological architecture that is not only modular but also structured around a core and a periphery. In this view, "a platform architecture partitions a system into stable core components and variable peripheral components"; the platform itself is constituted by the stable core of the product system (emphasis added) (Baldwin and Woodard, 2009, p. 24).

Facilitating innovation is therefore what platforms, as modular systems, are particularly good for. The central tenet of the modularity literature is precisely that modular product architectures facilitate innovation (Langlois and Robertson, 1992; Baldwin and Clark, 2000; Schilling, 2000). This is because, first, modularity helps manage complexity: by breaking up a complex system into discrete components, which interact through standardized interfaces within a standardized architecture, one can eliminate what would otherwise be an unmanageable spaghetti tangle of systemic interconnections (Simon, 1962; Parnas, 1972; Langlois, 2002). The second and related reason is that modularity, by reducing the interdependencies between modules to simple interconnectivity rules, reduces the scope of information that designers need to design their modules, and allows a specialization and division of innovative labour. This facilitates autonomous innovation within modules, as well as mix-and-match innovation through innovative recombination of modules (Garud and Kumaraswamy, 1995).

The role of "interfaces" is therefore fundamental to how modularity facilitates innovation. A modular architecture divides all the information required to build the system into visible and hidden information. For Baldwin and Clark, "when the complexity of one of the elements crosses a certain threshold, that complexity can be isolated by defining a separate abstraction that has a simple interface. The abstraction hides the complexity of the element; the interface indicates how the element interacts with the larger system" (Baldwin and Clark, 2000, p. 64). For Baldwin (2008), a physical

\footnotetext{
4 Ulrich (1995) defines product architecture as "the scheme by which the function of a product is allocated to physical components" (Ulrich, 1995, p. 419), and more precisely as: (1) the arrangement of functional elements; (2) the mapping from functional elements to physical components; (3) the specification of the interfaces among interacting physical components (Ulrich, 1995, p. 422). For Baldwin and Clark (2000, p. 63), "An architecture specifies what modules will be part of the system and what their functions will be"; while "interfaces" describe in detail how modules will interact, including how they fit together and communicate.
} 
interface between modules becomes the physical embodiment, or material instantiation, of the division of labour between different teams. The interface is therefore a divider (of labour between distinct teams), but also a connector, and a conduit of selected information facilitating interconnection.

The degree of "openness" of interfaces will therefore have an influence on the extent to which this facilitation of innovation can happen. The concept of open interfaces can be a fuzzy one (West, 2007) but I take it here in the commonly understood sense of the interface contains information that is accessible to external agents and usable by them to allow to build complementary innovation that is compatible with this interface. While modular innovation can happen within a firm if all relevant information is shared within the firm members, innovation can also be facilitated at the industry level, depending on how open the interfaces between modules are (Langlois and Robertson, 1992).

In the context of platforms, opening a system to complementary development affects innovation by drawing on a wider set of accessible external capabilities and distributed heterogeneous knowledge (Chesbrough, 2003), as well as independent experimentation.

In summary, the engineering view interprets platforms as purposefully designed technological architectures (including interfaces) that facilitate innovation. This view says that the design and use of platforms helps firms achieve economies of scope in production and design - allowing for economies of scope in innovation. While it is extremely useful to understand how platforms stimulate innovation, the engineering design perspective on platforms has several important limitations. This perspective sees essentially platforms as structurally stable: innovation happens on modules, within stable system architectures, and facilitated by stable interfaces; this view therefore does not help explain how platforms themselves evolve (that is, how what Baldwin and Woodard (2009) would call the "core", evolves). In addition, this stream of research does not provide insights on competition between platforms (which the economics literature does), and it fails to take into account the possible competition between platform owners and complementors (which the economics literature also ignores).

While the thrust of the engineering design literature is summarized above, recent developments in management research have extended it in directions that attempt to articulate how platform innovation and platform competition interact over time. For example Boudreau (2010) presents an empirical study of mobile handheld platforms, and finds an inverted U-shape relationship between innovation and opening platform access, consistent with a "crowding out" of innovation incentives when competition among complementors increase beyond a certain level, a hypothesis confirmed in Boudreau (2012).

\section{Toward an integrative framework for platforms}

\subsection{Motivation}

The reality of platform dynamics, and in particular of how competition and innovation interact, is more complex than the one drawn by Boudreau $(2010,2012)$ and Eisenmann et al. (2009, 2011). They analyze competition between platforms as well as competition between complementors. However, neither addresses the question of competition between the platform owner and its complementors, which frequently occurs in platform-based ecosystems.

Consider for example the shifting relationship between Google and Apple, and between Facebook and Google, in the mobile sector. Apple used to bundle Google Maps as a part of the iPhone homescreen, but the iPhone5 replaced it with its own Apple maps application. Facebook has used Google's Android' APIs ${ }^{5}$ to develop its mobile phone "homescreen" application, thus shifting from being a complementor to competing directly with Google for endusers' attention and advertising revenues. Earlier examples include the shifting relationship between Netscape and Microsoft in the late 1990s: Netscape started as a complementor to Windows, but its success caused Microsoft to treat it as a competitor, triggering the "envelopment" of the browser with the introduction Internet Explorer.

The opposite dynamic can also occur, when competitors ally to create a common platform. In the late 1990s, Symbian rallied a coalition of competing mobile handset manufacturers (Nokia, Ericsson, Motorola, Siemens), in order to attempt to create a smartphone operating system which would forestall Microsoft's entry into the mobile market.

In addition, the fixed roles imposed on agents by the previous literatures restricted them to either being consumers (per the double-sided market literature) or collaborative innovators (per the engineering design literature). These do not reflect common empirical patterns of how a number of platforms operate and evolve, since in today's digital economy users often play both roles in non-separable ways.

Consider for example the case of important contemporary digital platforms such as Google or Facebook. While end-users "consume" the service (search, social networking) offered by these platforms, they also constantly "feed", individually and collectively, their personal data into these platforms (as expressed by the items they search, their location, their preferences as revealed by previous queries, and their personal connections data), thereby providing the very data upon which these platforms draw upon to deliver its services. Users play therefore the role of (generally unpaid) contributors to the supply of (and further innovation on) the platform itself.

Agents' changing roles within platform-based ecosystems (from complementor to competitor for example, or vice versa) and associated shifting patterns of collaboration and competition, are in fact a feature of ecosystems (Iansiti and Levien, 2004), one that ought to be treated explicitly in rigorous attempts to theorize technological platforms. This is particularly relevant for digital platforms, as Baldwin and von Hippel (2011) suggest that the transition to increasingly digitized and modularized design and production practices, coupled with the availability of very-lowcost, Internet-based communication, is creating a "paradigm shift" whereby innovation is not restricted to producers anymore, but that users are increasingly able and willing to engage in distributed and collaborative innovation.

We therefore need a theoretically sound, integrated conceptualization of platforms that allows multi-modal interaction between agents within and across platforms, and that would allow scholars to study the ways in which competition and innovation shape the way platforms evolve. In the next section I develop such a conceptualization, and argue for the value of analyzing platforms through an organizational lens.

\footnotetext{
${ }^{5}$ An application programming interface (API) is defined by the Software Engineering Institute as "a technology that facilitates exchanging messages or data between two or more different software applications." ("Application Programming Interfaces," vol. 2004: Software Engineering Institute - Carnegie Mellon University, 2003). In other words, an API refers to a software interface that defines the service that one component, module, or application provides to others software elements. Generally invisible to end-users, APIs are carefully thought out pieces of code created by programmers for their applications that allow other applications to interact with their application.
} 
Table 2

A classification of technological platforms.

\begin{tabular}{|c|c|c|c|}
\hline & Internal platform & Supply-chain platform & Industry platform \\
\hline Level of analysis & - Firm & - Supply-chain & - Industry ecosystems \\
\hline $\begin{array}{l}\text { Platform's constitutive } \\
\text { agents }\end{array}$ & $\begin{array}{l}\text { - One firm } \\
\text { - Its constituent sub-units }\end{array}$ & $\begin{array}{l}\text { - Assembler } \\
\text { - Suppliers }\end{array}$ & $\begin{array}{l}\text { - Platform leader } \\
\text { - Complementors }\end{array}$ \\
\hline $\begin{array}{l}\text { Technological } \\
\text { architecture }\end{array}$ & \multicolumn{3}{|c|}{$\begin{array}{l}\text { - Modular design } \\
\text { - Core and periphery }\end{array}$} \\
\hline Interfaces & $\begin{array}{l}\text { - Closed interfaces } \\
\text { Interfaces specifications are } \\
\text { shared within the firm, but not } \\
\text { disclosed externally }\end{array}$ & $\begin{array}{l}\text { - Interfaces selectively open } \\
\text { Interface specifications are shared } \\
\text { exclusively across the supply-chain }\end{array}$ & $\begin{array}{l}\text { - Open interfaces } \\
\text { Interface specifications are shared } \\
\text { with complementors }\end{array}$ \\
\hline $\begin{array}{l}\text { Accessible innovative } \\
\text { capabilities }\end{array}$ & - Firm capabilities & - Supply-chain's capabilities & - Potentially unlimited pool of external capabilities \\
\hline $\begin{array}{l}\text { Coordination } \\
\text { mechanisms }\end{array}$ & $\begin{array}{l}\text { - Authority through } \\
\text { managerial hierarchy }\end{array}$ & $\begin{array}{l}\text { - Contractual relations between supply-chain } \\
\text { member organizations }\end{array}$ & $\begin{array}{l}\text { - Ecosystem governance } \\
\circ \text { In the special case of multi-sided } \\
\text { markets: exclusively through pricing }\end{array}$ \\
\hline Literature & $\begin{array}{l}\text { - Sanderson and Uzumeri (1995) } \\
\text { - Meyer and Lehnerd (1997) } \\
\text { - Simpson (2004) }\end{array}$ & $\begin{array}{l}\text { - Brusoni (2005) } \\
\text { - Zirpoli and Becker (2011) } \\
\text { - Sako (2009) }\end{array}$ & $\begin{array}{l}\text { - Gawer and Cusumano (2002) } \\
\text { - Baldwin and Woodard (2009) } \\
\text { - Boudreau (2010) } \\
\text { - Eisenmann et al. (2011) }\end{array}$ \\
\hline Examples & $\begin{array}{l}\text { - Black and Decker (machine tools) } \\
\text { - Sony Walkman (consumer } \\
\text { electronics) }\end{array}$ & $\begin{array}{l}\text { - Renault-Nissan (automotive manufacturing) } \\
\text { - Boeing (aerospace manufacturing) }\end{array}$ & $\begin{array}{l}\text { - Facebook (social networking) } \\
\text { - Google (Internet search and advertising) } \\
\text { - Apple iPhone and Apps (Mobile) }\end{array}$ \\
\hline
\end{tabular}

\subsection{Parameters of the framework}

In the previous section I established that, underlying their obvious differences, the economics and the engineering design perspectives share a common important conceptual underpinning: in order to create value, platforms rely crucially on economies of scope in supply and innovation (for the engineering design view), and economies of scope in demand (for the economics view). Given the centrality of economies of scope in theories of organizations (Teece, 1980; Wernerfelt, 1984; Helfat and Eisenhardt, 2004), this common underpinning provides the intuition that an organizational lens might be useful to develop a unifying framework for platforms. By organization I do not necessarily mean one firm or one legal entity, nor one type of organizational form but rather, returning to a fundamental definition of what organizations are (Barnard, 1938, p. 73), a "system of coordinating activities of two or more persons", without any a priori as to the organizational form it might take.

A key conceptual barrier to bridging current perspectives on platforms may lie in their respective fixed assumptions about the organizational form that platforms take. In order to develop a unified framework I allow the organizational form to be an endogenous variable.

In addition, we have seen that in today's digital economy, users often play both roles (consumer, innovator) in non-separable ways. To develop a versatile yet unified framework for technological platforms, it might therefore be useful to refrain from pre-determining a priori whether the agents who constitute it play the role of "supply" or "demand". Let us therefore allow multi-modal interaction and possibly evolving interaction between platforms' constitutive agents.

A unified framework for platforms should therefore not impose a priori the organizational context within which they occur, whether within firms or across markets. It would present platforms in the diverse ways in which as they appear in reality, in different organizational contexts and at different levels of analysis, and highlight their essential characteristics. It should also allow multimodal interaction between platform agents, either within or across platforms.

In order to further develop this framework, I present a classification system based on an analysis of the various platform literatures and associated key examples (Table 2). Table 2 classifies platforms within three increasingly broader organizational settings: within firms, across supply-chains, and within ecosystems. Each of the three organizational settings has a corresponding type of platform, for which I have highlighted: the level of analysis; the platform's constitutive agents; its technological architecture; the nature of its interfaces; its innovative capabilities; and its coordination mechanisms. In addition, a representative set of relevant empirical examples has been included, along with key research articles.

Table 2 highlights the following results.

First, the phenomenon of platforms is observable at different levels of analysis and in various organizational settings: within firms, across supply-chains, and across industry ecosystems.

Second, depending on the organizational setting, the constitutive agents of the platform are: a firm and its sub-units (in internal platforms); or an assembler and its suppliers (in supply-chain platforms); or, a platform leader and its complementors (in industry platforms).

Third, all platforms share a common modular architecture organized around a core and a periphery. This is a confirmation of Baldwin and Woodard (2009) intuition. This common technological architecture constitutes therefore a constant throughout all kinds of platforms, and cuts across all organizational forms.

Fourth, all platforms have technological interfaces (between the "core" and the "periphery") and, depending on whether they are within firms, within supply-chains, or within ecosystems, these interfaces are closed, semi-closed, or open. As explained earlier (and as in West, 2007), the concept of open interface is never black and white, and even within ecosystems, there are variations within the spectrum of how open these interfaces are. For example, Apple's iPhone ecosystem has been described as a "walled garden" (Hazlett et al., 2011), while Google Android's operating system has been seen as "more open", and open source software has been seen as a purely open ecosystem. But generally as one moves from internal platforms (within firms) to industry platforms (within ecosystems), interfaces become more open.

Fifth, as the scope of the platform broadens from internal platform through supply-chain platform and on to industry platform, the platform's access to innovating agents and their diverse 
capabilities increases. While for firm-level platforms the sources of innovation are restricted to within the focal firm, and for supplychain platforms within the focal firm's pool of suppliers, within ecosystems, innovators could be anyone, and may be found anywhere. The platform owner may not know ex-ante who or where innovators may be. In fact, an interesting specificity of industry platforms is that an industry platform owner does not need to know ex-ante who a complementary innovator might be. Potential innovators of complementary products self-identify to the platform owner, and can utilize the codified information on platform connectors (such as APIs) and programming tools that are disclosed by platform owners to build compatible complements. Industry platforms therefore reduce the platform owner's search cost for complementary innovators and extend the pool of accessible innovative capabilities that will indirectly create value for the platform.

Sixth, the coordination mechanisms operating within internal platforms are those of the managerial hierarchy, those operating across supply-chains are buyers-suppliers contracts, and within ecosystems the coordination is ensured by ecosystem governance, a point which I shall return to later.

The resulting classification system supports a unified view of platforms in that it highlights that the different types of platforms described in the different platform literatures, far from ascribing to fundamentally different phenomena, constitute in fact various manifestations of an underlying similar phenomenon.

The previous analysis supports therefore a unified conceptualization of platforms as organizations, as follows: Technological platforms can be usefully seen as evolving organizations or metaorganizations that: (1) federate and coordinate constitutive agents who can innovate and compete; (2) create value by generating and harnessing economies of scope in supply or/and in demand; and (3) entail a technological architecture that is modular and composed of a core and a periphery.

The reason the new conceptualization specifies that the platform federates and coordinates (as opposed to simply "coordinates") its agents is because it recognizes that neither the existence nor the process of federation of complementors into a collective can be taken for granted, especially in the context of industry ecosystems. While within firms, and to some extent within supply-chains, the commonality of objectives among constitutive agents could perhaps be taken for granted, the federation of innovative and autonomous agents can certainly not be taken for granted within innovative ecosystems. Absent managerial hierarchy or supplychain authority, an important role for platforms within industry ecosystems is precisely to ensure federation so that coordination amongst agents can happen. Federation cannot be taken for granted, and, without federation and without contracts, there is no basis for coordination. Hence, the importance of ecosystem governance (Tiwana et al., 2010) for building and sustaining legitimacy of the platform leader (Gawer and Henderson, 2007) as well as for fostering a collective identity for ecosystem members (Gawer and Phillips, 2013).

This conceptualization is theoretically consistent with both the economic perspective and the engineering view perspective. It is consistent with the engineering design perspective in that the condition of modular architecture and the core-periphery structure are maintained throughout all categories of platforms. With regard to the economic perspective, this conceptualization considers the perspective of platforms as double-sided markets as an important special case of industry platforms, one in which the relationships between the platform's constitutive agents are purely transactional, and where the pricing mechanism is the principal mode of coordination among platform agents.

While it builds on the previous literatures, my proposed conceptualization of platforms as evolving organizations or metaorganizations relaxes their most problematic assumptions: in contrast with the economics view, the proposed conceptualization does not assumes that the constitutive agents of the platform play a fixed role (that of a buyer); and in contrast with the engineering view, it does not assume that they necessarily play the fixed role of a complementor - nor does it assume that the platform interfaces are stable. I propose instead that the conceptualization of platform acknowledges that the roles played by the platform's constitutive agents can evolve over time. Without autonomous agents and ecosystem governance, an industry platform is just a technological architecture, an agent-less structure.

By conceptualizing platforms as organizations, I re-introduce agency in the concept of platforms, which had disappeared in the engineering view of platforms, while not discarding the important structural characteristic of their architecture (core-periphery). By bringing to the fore the platform's constitutive agents and allowing them a multiplicity of modes of interaction that are theoretically and empirically consistent with how platforms create value, the framework takes one step towards uncovering micro-foundations of how platforms operate and evolve.

\section{Platform innovation and competition}

As an illustration of how to use the framework detailed above, I now infer from it a simple model of patterns of innovation and competition that can be associated with technological platforms, and which could be tested by other scholars.

\subsection{Patterns of platform innovation and competition}

The framework has highlighted that for each type of platform (internal, supply-chain, industry platform) there is a corresponding coherent set of attributes (organizational form, interfaces, set of accessible capabilities, governance). Rather than representing them as a discrete set of rigidly delineated configurations of attributes, one can represent them as inscribed in a continuum (Fig. 1).

Fig. 1 aims to represent the organizational continuum of technological platforms, where for each degree of interface openness, there is a corresponding organizational form, a set of accessible capabilities, and a corresponding type of governance. By calling it a continuum and designing a visual representation of a set of parallel arrows, I aim to convey the intuition that there is a kind of fluidity, and possible evolutionary pathways, between these configurations.

To illustrate how internal platforms can evolve towards industry platforms, consider the case of the historical evolution from computer mainframes to personal computers spanning three decades. In the mid-1960s, IBM, the industry leader in mainframes, engaging in a radical redesign of mainframe computer, created with the IBM System/360 an internal modular platform for future families of IBM mainframes (Fisher et al., 1983). At that time, the specification IBM System/360 interfaces were closed, and only known to IBM engineers. But the modular architecture of System/360 offered the technical possibility for other firms to create modules that would "slot in" on "plug-in" to the architecture. Soon after the introduction of System/360, a large number of companies poached key IBM engineers and started to offer "plug-compatible" peripherals including disk drives, terminals, printers, and memory devices (Baldwin and Clark, 2000). So, in the 1970s and early 1980s, the IBM System/360 gave rise to "plug-compatible" products within a supply chain. When IBM decided to enter the new micro-computer category with the IBM PC in the early 1980s, it built it with off-the shelf parts from the new supply chain, for example from Intel and Microsoft.

In the mid to late 1980 s, a number of firms began commercializing copies of the IBM PC, and an ecosystem of firms grew outside of IBM's supply chain. Pushing their advantage, Intel and Microsoft recognized that they could further weaken IBM by steering the 


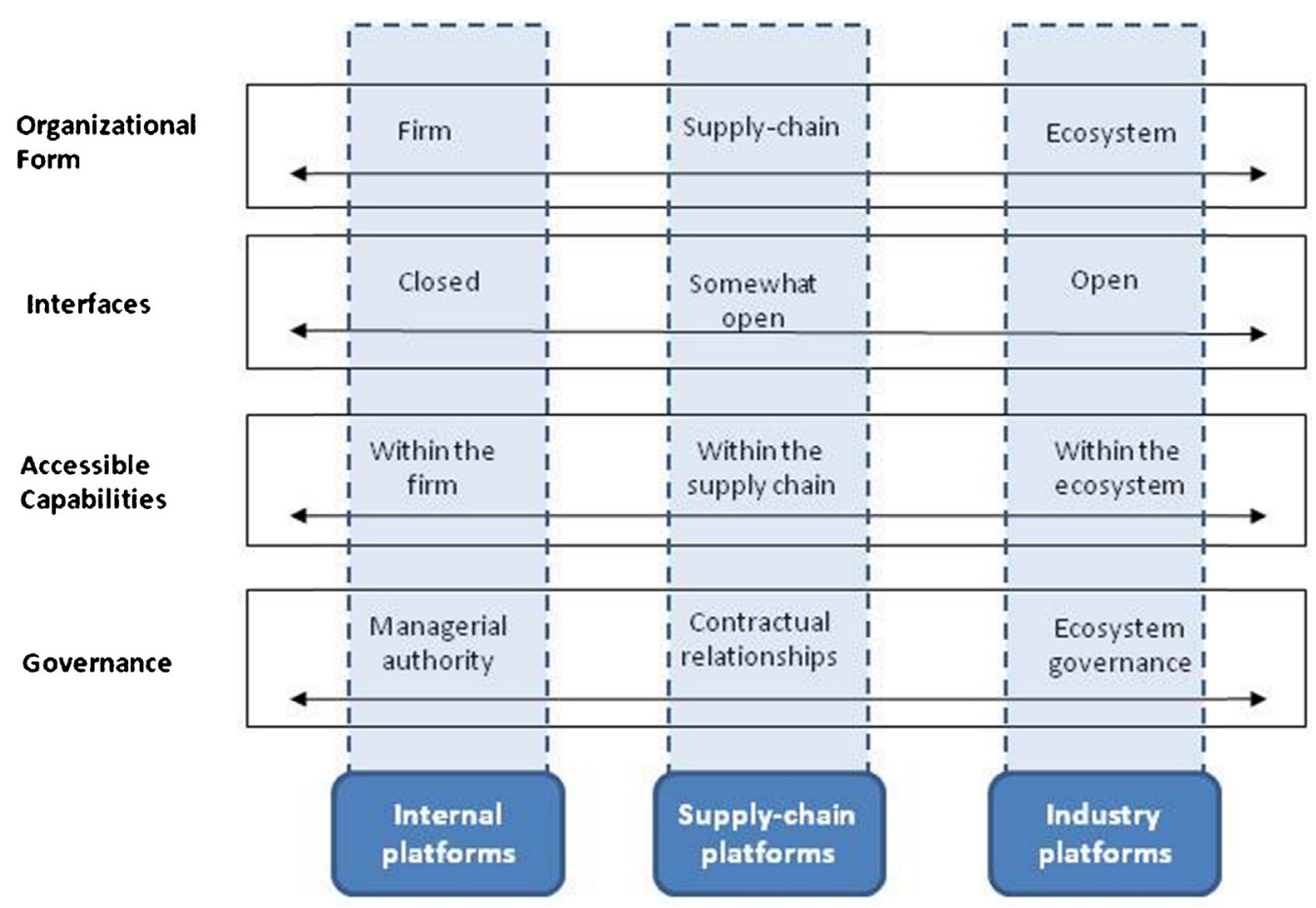

Fig. 1. The organizational continuum of technological platforms.

development of the PC architecture towards Intel's microprocessors and Microsoft's operating system. As IBM gradually lost control over its supply chain, the supply-chain platform evolved into an industry platform in the 1990s, with Intel and Microsoft seizing platform leadership (Gawer and Cusumano, 2002). In particular, Intel innovated on the architecture of the overall PC system by creating open interfaces allowing faster interconnections between elements of the PC, and freely shared the intellectual property of its interfaces. Intel's process of orchestrating industry-wide complementary innovation in a way that protected complementors' incentives helped establish the continued support of an ecosystem of firms whose business models were tied to the new, open 'Wintel' (Windows + Intel) PC architecture, which had by then become the industry platform (Gawer and Phillips, 2013).

One can use the framework to unpack how innovation and competition interact along the organizational continuum described in Fig. 1. Design decisions on technological interfaces, as well as governance decisions, can be expected to have an effect on the platform agents' incentives to collaborate, to innovate, and/or to compete.

As the platform scope broadens from internal to supply-chain to industry platform, access to innovating agents and their diverse capabilities increases. This implies that the potential for collaborative innovation is increased as one moves (figuratively) from internal to supply-chain to industry platforms.

But at the same time, as one moves from internal to supply-chain to ecosystem platforms, the likelihood of competition between constitutive agents of the platform is also likely to increase. This is because within firms, while competition between teams is theoretically curtailed by the managerial hierarchy and within supply chains, competition between the platform owner and its suppliers is also kept in check through appropriate contracts that maintain incentives for cooperation. Within ecosystems however, agents are autonomous, and cooperation between platform owner and complementors cannot be taken for granted. Ecosystems' loose, unstructured relationships offer neither contractual safeguards against opportunistic or competitive behaviour, nor high-powered incentives for cooperation. In addition, as Pil and Cohen (2006) and Ethiraj et al. (2008) have established, while modularization enables performance gains through innovation, at the same time, it also sets the stage for those gains to be eroded through competition and imitation. It is therefore to be expected that competition will occur among platform owners and complementors within industry ecosystems. From this I infer the following hypotheses:

H1. As platform interfaces become more open, more agents will be attracted into the platform ecosystem, and the platform leader will be able to access a larger set of potentially complementary innovative capabilities.

As an illustration, consider how Google, Twitter, Flickr, Amazon, and Facebook have developed and shared Application Programming Interfaces (APIs) to encourage independent software developers to utilize these platforms' web services and incorporate them within their own platform-complementary innovations. For example, as of February 2014, Google had published 51 APIs, ${ }^{6}$ for almost all of Google's popular consumer products such as Google Maps, YouTube, Google Search, and many others. These APIs are a key resource for the digital platforms' ecosystem developers, allowing them to access the platform user data and build applications. They are also a key resource for platform owners who then have access to external developers and derive value from their platformcomplementary innovations.

H2. While a large proportion of the platform ecosystem's agents will innovate in ways that are complementary to the platform, a number of them will start innovating in ways that become competitive to the platform.

As an illustration, consider how Facebook launched in 2013 its mobile phone "homescreen" application, Facebook Home, which it had developed using Google's Android, thus shifting from being a complementor in Google's Android ecosystem to competing directly with Google for end-users' attention and advertising revenues on mobile. Consider also how, in 2013, internet on-demand video streaming service provider Netflix started to develop its own

\footnotetext{
6 Source: https://developers.google.com/apis-explorer/\#p/ (accessed 20.02.14).
} 


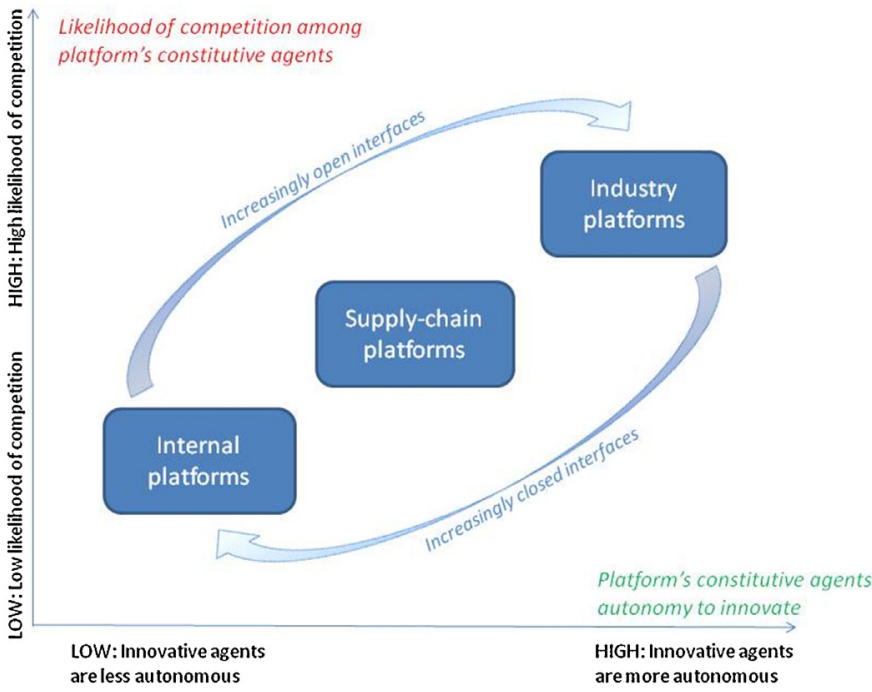

Fig. 2. Platform innovation and competition.

high-quality original programming content, thereby competing with traditional content providers such as television network HBO in relation to whom it was until then acting as a complementor. ${ }^{7}$

H3. Emergence of competition from complementors will depend on the governance of the ecosystem, as collaborative governance will increase complementors' incentives to innovate in platformenhancing ways.

In well-governed ecosystems, the platform leader will seek to preserve the alignment of interests of ecosystem members, and will take care to protect complementors' margins. Intel for example took particular care to ensure that its complementors could remain profitable by refraining to compete directly with them in a number of markets (Gawer and Henderson, 2007). Conversely, Microsoft's policy of "embrace and extend" towards Netscape and Java in the mid 1990s, was allegedly used to weaken and dislodge complementors who were perceived as competitive threats; Microsoft argued in its defence that this was demand-driven.

H4. Emergence of competition from former complementors is in turn likely to create a reaction by the platform leader to start competing back with these former complementors-turned-rivals, either by enveloping them, or by closing its technological interface, in effect moving away from being an industry platform towards becoming a supply-chain platform.

As an illustration, consider how Twitter changed the rules of its API and restricted its use in 2012, henceforth preventing users' Tweets from appearing on the rival social networking platform LinkedIn (which had hitherto been treated as a complementor), as an attempt to stop fuelling the growth of LinkedIn with Twitter content, and to corral users back onto its own site where their attention could be monetized through advertising sales. ${ }^{8}$ Another example is when Apple stopped offering Google Maps as pre-installed application on its new iPhone iOS6 in 2012, following up on Google's refusal to provide turn-by-turn navigation for maps on the iPhone - a valuable feature that was available on Google's own Android operating system for smartphones. ${ }^{9}$

\footnotetext{
7 Source: "Punching above its weight, upstart Netflix pokes at HBO", The New York Times, 16 Feb., 2014

8 Source: http://linkedinprofileservice.co/linkedin-profile/linkedin-profiles/ twitter-stops-no-longer-displays-tweets-on-linkedin-profiles/ (accessed 20.02.14).

9 Source: http://www.theguardian.com/technology/2013/nov/11/apple-mapsgoogle-iphone-users.
}

Fig. 2 summarizes these hypotheses.

This small set of hypotheses, logically derived from the framework and consistent with anecdotal evidence, indicate one of the possible pathways through which platforms may evolve. They obviously require empirical testing, preferably in a variety of empirical settings. Such empirical testing is outside the scope of this article and would constitute a fruitful avenue for further research.

\section{Discussion and conclusion}

\subsection{Discussion}

This paper makes two main contributions: to have summarized and bridged the two prevailing conceptualizations of technological platforms, and to have developed a new theoretical framework for platforms, culminating in a new conceptualization of platforms as evolving organizations or meta-organizations. Building on a classification system of different kinds of platforms, I have proposed that platforms operate along an organizational continuum, including firms, supply chains, and industry ecosystems. I have then derived hypotheses about patterns of platform innovation and competition.

Conceptualizing platforms as evolving organizations or metaorganizations possesses distinct advantages. It is consistent with existing theories from economics and engineering design, and while it has built on the previous literatures, it has relaxed their most problematic assumptions: it does not require us to assume that the constitutive agents of the platform play a fixed role, be that buyer or a complementor - nor does it assume that the platform interfaces are stable. Instead this conceptualization acknowledges that the roles played by the platform's constitutive agents can be multiple and evolve over time. Also, conceptualizing platforms as organizations or meta-organizations re-introduces agency in the concept of platforms, which had disappeared in the engineering view of platforms, without discarding the important structural characteristic of their architecture (core-periphery). By focusing on agents' behaviour and structural characteristics, the framework makes explicit the micro-foundations of how platforms operate, and begins to provide a unified theoretical foundation to help analyze innovation and competition within and across platforms.

\subsection{Managerial implications}

Platform leaders within ecosystems face the important and difficult task of attracting and incentivizing a potentially limitless number of innovative yet autonomous agents to act in ways that are platform-enhancing, as opposed to platform-indifferent or even possibly platform-competing. As such, platform leaders are required to nurture their ecosystems and cannot resort to the traditional modes of governance available within firms or supply-chains, namely managerial hierarchy or suppliers-buyers contracts. Ecosystem governance is therefore essential to platforms competitive and innovative performance.

This implication is consistent with previous research by Gawer and Cusumano (2002, 2008), Cusumano (2010), Boudreau and Hagiu (2009), and Tiwana et al. (2010), who have explored the effectiveness of combinations of managerial choices leading firms to obtain and sustain positions as platform leaders. Future practice-relevant research could also develop further managerial implications that might benefit firms that aim to dethrone established platforms (Suarez and Kirtley, 2012).

\subsection{Limitations and avenues for further research}

The proposed framework constitutes one step in the direction of strengthening the theoretical foundations for research on platforms, and has obvious limitations. First, it is a theory-building 
effort that requires future systematic empirical validation. Further, it only begins to explore the complex patterns of interaction between innovation and competition within and across platforms, and does not provide answers to a number of important questions. For example, how do decisions about platform scope (such as envelopment) and degree of platform openness interact? Also, what are the drivers and consequences of changes in the degree of openness of platforms as they evolve over time? In addition, the concept of economies of scope in innovation was discussed only briefly here, and requires further theoretical elaboration.

Promisingly however, the organizational lens proposed by this new framework allows future researchers to tap into the vast organizational theory literature, and in particular on organizational evolution, to illuminate poorly understood aspects of platform dynamics. This opens up an important set of avenues for future research.

For example, scholars could use the framework developed here to develop hypotheses on how platforms set out their boundaries, by following the same logic that organizations use to set out their organizational boundaries - a process that can be interpreted differently depending on the theoretical conception of organizations that one adopts. One fruitful avenue might be for example to build on Santos and Eisenhardt (2005)'s comprehensive theory on organizational boundaries, and apply it to platforms.

Another promising avenue for further research, building on a different branch of organizational theory, would be to connect the literature on platforms to the literature on inter-organizational network dynamics (Powell et al., 1996, 2005; Uzzi, 1997; Ahuja, 2000; Brass et al., 2004; Dhanaraj and Parkhe, 2006; Zaheer et al., 2000) to derive insights on patterns of emergence and evolution of platform ecosystems as networks of innovators. Given the growing importance of technological platforms, the development of a more precise and nuanced understanding of platform emergence and evolution promises to be a fertile area of further study.

\section{Acknowledgements}

Financial support from the EPSRC NEMODE Network+ grant on Platforms as New Economic Models in the Digital Economy is gratefully acknowledged. I am indebted to Michael Cusumano, Michael Jacobides, Rebecca Henderson, John-Paul MacDuffie, Anita McGahan, Nelson Phillips, and David Bendor for helpful comments. Previous versions of this paper were presented at the DRUID Summer Conference 2012, the Academy of Management Annual Meeting in Boston 2012 and the British Academy of Management 2013.

\section{References}

Adner, R., Kapoor, R., 2010. Value creation in innovation ecosystems: how the structure of technological interdependence affects firm performance in new technology generations. Strategic Management Journal 31 (3), 306-333.

Ahuja, G., 2000. The duality of collaboration: inducements and opportunities in the formation of interfirm linkages. Strategic Management Journal 21 (3), 317-343.

Ahrne, G., Brunsson, N., 2005. Organizations and meta-organizations. Scandinavian Journal of Management 21 (4), 429-449.

Armstrong, M., 2006. Competition in two-sided markets. RAND Journal of Economics 37, 668-691

Baldwin, C.Y., 2008. Where do transactions come from? Modularity, transactions, and the boundaries of firms. Industrial and Corporate Change 17 (1), 155-195.

Baldwin, C.Y., Clark, K.B., 2000. Design Rules: The Power of Modularity, vol. 1. MIT Press, Cambridge, MA.

Baldwin, C.Y., von Hippel, E., 2011. Modeling a paradigm shift: from producer innovation to user and open collaborative innovation. Organization Science 22 (6), 1399-1417.

Baldwin, C.Y., Woodard, J.J., 2009. The architecture of platforms: a unified view. In: Gawer, A. (Ed.), Platforms, Markets and Innovation. Edward Elgar, Cheltenham, UK and Northampton, Mass, pp. 19-44

Barnard, C.I., 1938. The Functions of the Executive. Harvard Business School Press, Boston, MA.
Boudreau, K.J., 2010. Open platform strategies and innovation: granting access vs. devolving control. Management Science 56 (10), 1849-1872.

Boudreau, K.J., 2012. Let a thousand flowers bloom? An early look at large numbers of software app developers and patterns of innovation. Organization Science 23 (5), 1409-1427

Boudreau, K.J., Hagiu, A., 2009. Platform rules: multi-sided platforms as regulators In: Gawer, A. (Ed.), Platforms, Markets and Innovation. Edward Elgar, Cheltenham, UK and Northampton, Mass, pp. 163-191.

Brandenburger, A., Nalebuff, B.J., 1997. Co-opetition. Currency Doubleday, New York

Brass, D.J., Galaskiewicz, J., Greve, H.R., Tsai, W., 2004. Taking stock of networks and organizations: a multilevel perspective. Academy of Management Journal 47 (6), 795-817.

Bresnahan, T.F., Trajtenberg, M., 1995. General purpose technologies 'Engines of growth'? Journal of Econometrics 6 (1), 83-108.

Brusoni, S., 2005. The limits to specialization: problem solving and coordination in 'modular networks'. Organization Studies 26 (2), 1885-1907.

Brusoni, S., Prencipe, A., 2009. Design rules for platform leaders. In: Gawer, A. (Ed.), Platforms, Markets and Innovation. Edward Elgar, Cheltenham, UK and Northampton, Mass, pp. 306-321.

Caillaud, B., Jullien, B., 2003. Chicken and egg: competition among intermediation service providers. RAND Journal of Economics 34, 309-328.

Chesbrough, H.W., 2003. Open Innovation: The New Imperative for Creating and Profiting from Technology. Harvard Business School Press, Boston, MA.

Clark, K.B., 1985. The interaction of design hierarchies and market concepts in technological evolution. Research Policy 14 (5), 235-251.

Cusumano, M.A., 2010. Staying Power: Six Enduring Principles for Managing Strategy and Innovation in an Uncertain World (Lessons from Microsoft, Apple, Intel, Google, Toyota and More). Oxford University Press.

Dhanaraj, C., Parkhe, A., 2006. Orchestrating innovation networks. Academy of Management Review 31 (3), 659-669.

Doran, D., 2003. Supply chain implications of modularization. International Journa of Operations and Production Management 23 (3), 316-326.

Dougherty, D., Dunne, D., 2011. Organizing ecologies of complex innovation. Organization Science 22 (5), 1214-1223.

Eisenmann, T., Parker, G., Van Alstyne, M., 2006. Strategies for two-sided markets. Harvard Business Review 84 (10), 92-101.

Eisenmann, T., Parker, G., Van Alstyne, M., 2009. Opening platforms: how, when, and why? In: Gawer, A. (Ed.), Platforms, Markets and Innovation. Edward Elgar Cheltenham, UK and Northampton, Mass, pp. 131-162.

Eisenmann, T., Parker, G., Van Alstyne, M., 2011. Platform envelopment. Strategic Management Journal 32 (12), 1270-1285.

Ethiral, S.K., Levinthal, D., Roy, R.R., 2008. The dual role of modularity: innovation and imitation. Management Science 54 (5), 939-955

Evans, D.S., 2003. Some empirical aspects of multi-sided platform industries. Review of Network Economics 2 (3)

Evans, D.S., Hagiu, A., Schmalensee, R., 2006. Invisible Engines: How Software Platforms Drive Innovation and Transform Industries. MIT Press, Cambridge, MA.

Evans, D.S., Schmalensee, R., 2008. Markets with two-sided platforms? Issues in Competition and Law and Policy (ABA Section of Antitrust Law) 1 (28), 667-693.

Fisher, F., McGowan, J.J., Greenwood, J.E., 1983. Folded, Spindled and Mutilated: Economic Analysis and U.S. vs. IBM. MIT Press, Cambridge, MA

Garud, R., Kumaraswamy, A., 1995. Technological and organizational designs to achieve economies of substitution. Strategic Management Journal 16, 93-110.

Gawer, A., 2009a. Platforms, markets and innovation: an introduction. In: Gawer A. (Ed.), Platforms, Markets and Innovation. Edward Elgar, Cheltenham, UK and Northampton, Mass, pp. 1-16.

Gawer, A., 2009b. Platforms, Markets and Innovation. Edward Elgar, Cheltenham, UK and Northampton, Mass

Gawer, A., 2009c. Platforms dynamics and strategies: from products to services. In: Gawer, A. (Ed.), Platforms, Markets and Innovation. Edward Elgar, Cheltenham, UK and Northampton, Mass, pp. 45-76.

Gawer, A., Cusumano, M.A., 2002. Platform Leadership: How Intel, Microsoft, and Cisco Drive Industry Innovation. Harvard Business School Press, Boston, MA

Gawer, A., Cusumano, M.A., 2008. How companies become platform leaders. MIT/Sloan Management Review 49 (2), 18-35

Gawer, A., Henderson, R., 2007. Platform owner entry and innovation in complementary markets: evidence from Intel. Journal of Economics and Management Strategy $16(1), 1-34$.

Gawer, A., Phillips, N., 2013. Institutional work as logics shift: the case of Intel's transformation to platform leader. Organization Studies 34 (8), 1035-1071

Gulati, R., Puranam, P., Tushman, M., 2012. Meta-organization design: rethinking design in interorganizational and community contexts. Strategic Management Journal 33 (6), 571-586

Hagiu, A., Wright, J., 2011. Multi-sided platform. Working Paper No. 12024. Harvard Business School.

Hazlett, T.W., Teece, D.T., Waverman, L., 2011. Walled garden rivalry: the creation of mobile network ecosystems. George Mason Law and Economics Research Paper No. 11-50., http://dx.doi.org/10.2139/ssrn.1963427.

Helfat, C.E., Eisenhardt, K.M., 2004. Inter-temporal economies of scope, organizational modularity, and the dynamics of diversification. Strategic Management Journal 25 (13), 1217-1232.

Huang, G.Q., Zhang, X.Y., Liang, L., 2005. Towards integrated optimal configuration of platform products, manufacturing processes, and supply chains. Journal of Operations Management 23 (3/4), 267-290. 
Iansiti, M., Levien, R., 2004. The Keystone Advantage: What the New Dynamics of Business Ecosystems Mean for Strategy, Innovation, and Sustainability. Harvard Business School Press.

Jiao, J.R., Simpson, T.W., Siddique, Z., 2007. Product family design and platformbased product development: a state-of-the-art review. Journal of Intelligent Manufacturing 18 (1), 5-29.

Katz, M.L., Shapiro, C., 1986. Technology adoption in the presence of network externalities. Journal of Political Economy 94 (4), 822-841.

Krishnan, V., Gupta, G., 2001. Appropriateness and impact of platform-based product development. Management Science 47, 52-68.

Langlois, R.N., 2002. Modularity in technology and organization. Journal of Economic Behavior \& Organization 49, 19-37.

Langlois, R.N., Robertson, P., 1992. Networks and innovation in a modular system: lessons from the microcomputer and stereo component industries. Research Policy 21 (4), 297-313.

MacDuffie, J.-P., 2013. Modularity-as-process and modularity-as-frame: lessons from product architecture initiatives in the global automotive industry. Global Strategy Journal 3 (1), 8-40.

MacDuffie, J.-P., Helper, S., 2006. Collaboration in supply chains with and without trust. In: Heckscher, C., Adler, P.S. (Eds.), The Firm as a Collaborative Community: Reconstructing Trust in the Knowledge Economy. Oxford University Press, Oxford, UK, pp. 417-466.

McGrath, M.E., 1995. Product Strategy for High-technology Companies. Irwin Professional Publishing, New York.

Meyer, M.H., Lehnerd, A.P., 1997. The Power of Product Platforms: Building Value and Cost Leadership. Free Press, New York.

Muffato, M., Roveda, M., 2002. Product architecture and platforms: a conceptual framework. International Journal of Technology Management 24 (1), $1-16$.

Nambisan, S., Sawhney, M., 2011. Orchestration processes in network-centric innovation: evidence from the field. Academy of Management Perspectives 25 (3), 40-57.

Panzar, J., Willig, R., 1975. Economics of scale and economies of scope in multi output production. Bell Laboratories Economic Discussion Paper (33).

Panzar, J.C., Willig, R.D., 1981. Economies of scope. Papers and Proceedings of the Ninety-third Annual Meeting of the American Economic Association, May, 1981. American Economic Review 71 (2), 268-272.

Parker, G., Van Alstyne, M., 2005. Two-sided network effects: a theory of information product design. Management Science 51, 1494-1504.

Parnas, D.L., 1972. On the criteria to be used in decomposing systems into modules. Communications of the ACM 15 (12), 1053-1058.

Pil, F.K., Cohen, S.K., 2006. Modularity: implications for imitation, innovation, and sustained advantage. Academy of Management Review 31 (4), 995-1011.

Powell, W.W., Koput, K.W., Smith-Doerr, L., 1996. Interorganizational collaboration and the locus of innovation: networks of learning in biotechnology. Administrative Science Ouarterly 41, 116-145.

Powell, W.W., White, D.R., Koput, K.W., Owen-Smith, J., 2005. Network dynamics and field evolution: the growth of interorganizational collaboration in the life sciences. American Journal of Sociology 110 (4), 1132-1205.

Robertson, D., Ulrich, K., 1998. Planning for product platforms. MIT Sloan Management Review 39 (4), 19-31.

Rochet, J.-C., Tirole, J., 2003. Platform competition in two-sided markets. Journal of the European Economic Association 1 (4), 990-1029.

Rochet, J.-C., Tirole, J., 2006. Two-sided markets: a progress report. RAND Journal of Economics 35, 645-667.

Rysman, M., 2004. Competition between networks: a study of the market for yellow pages. Review of Economic Studies 71 (2), 483-512.
Rysman, M., 2009. The economics of two-sided markets. Journal of Economic Perspectives 23 (3), 125-143.

Sanderson, S.W., Uzumeri, M., 1995. Managing product families: the case of the Sony Walkman. Research Policy 24 (5), 761-782

Santos, F.M., Eisenhardt, K.M., 2005. Organizational boundaries and theories of organization. Organization Science 16 (5), 491-508.

Sako, M., 2009. Outsourcing of tasks and outsourcing of assets: evidence from automotive suppliers parks in Brazil. In: Gawer, A. (Ed.), Platforms, Markets and Innovation. Edward Elgar, Cheltenham, UK and Northampton, Mass, pp. 251-272.

Schilling, M.A., 2000. Towards a general modular system theory and its application to interfirm product modularity. Academy of Management Review 25 (2), 312-334.

Simon, H.A., 1962. The architecture of complexity. Proceedings of the American Philosophical Society 106 (6), 467-482.

Simpson, T.W., 2004. Product platform design and customization: status and promise. AI EDAM: Artificial Intelligence for Engineering Design, Analysis and Manufacturing 18 (1), 3-20.

Simpson, T.W., Siddique, Z., Jiao, J., 2006. Platform-based product family development: introduction and overview. In: Simpson, T.W., Siddique, Z., Jiao, J. (Eds.), Product Platforms and Product Family Design: Methods and Applications. Springer, New York, pp. 1-16.

Sturgeon, T.J., 2002. Modular production networks: a new American model of industrial organization. Industrial and Corporate Change 11 (3), 451-496.

Suarez, F.F., Kirtley, J., 2012. Dethroning an established platform. MIT Sloan Management Review 53 (4), 35-41.

Tatsumoto, H., Ogawa, K., Fujimoto, T., 2009. The effect of technological platforms on the international division of labor: a case study of Intel's platform business in the PC industry. In: Gawer, A. (Ed.), Platforms, Markets and Innovation. Edward Elgar, Cheltenham, UK and Northampton, Mass, pp. 345-369.

Teece, D.J., 1980. Economics of scope and the scope of the enterprise. Journal of Economic Behavior and Organization 1, 223-247.

Teece, D.J., 1982. Towards an economic theory of the multiproduct firm. Journal of Economic Behavior and Organization 3 (1), 39-63.

Tiwana, A., Konsynski, B., Bush, A., 2010. Research commentary - platform evolution co-evolution of platform architecture, governance and environmental dynamics. Information Systems Research 21 (4), 675-687.

Ulrich, K., 1995. The role of product architecture in the manufacturing firm. Research Policy 24 (3), 419-440.

Uzzi, B., 1997. Social structure and competition in interfirm networks: the paradox of embeddedness. Administrative Science Quarterly 42, 35-67.

Wernerfelt, B., 1984. A resource-based view of the firm. Strategic Management Journal 5 (2), 171-180.

West, J., 2007. The economic realities of open standards: black, white, and many shades of grey. In: Greenstein, S., Stango, V. (Eds.), Standards and Public Policy. Cambridge University Press, Cambridge, UK, pp. 87-122.

Wheelwright, S.C., Clark, K.B., 1992. Creating project plans to focus product development. Harvard Business Review 70 (2), 67-83.

Wilbur, K.C., 2008. A two-sided, empirical model of television advertising and viewing markets. Marketing Science 27 (3), 356-378.

Zaheer, A., Gulati, R., Nohria, N., 2000. Strategic networks. Strategic Management Journal 21 (3), 203.

Zirpoli, F., Becker, M.C., 2011. The limits of design and engineering outsourcing: performance integration and the unfulfilled promises of modularity. R\&D Management 41 (1), 21-43.

Zirpoli, F., Caputo, M., 2002. The nature of buyer-supplier relationships in co-design activities: the Italian auto industry case. International Journal of Operations and Production Management 22 (12), 1389-1410. 